\title{
Induction of the immunoprotective coat of Yersinia pestis at body temperature is mediated by the Caf1R transcription factor
}

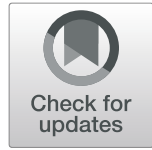

Abdulmajeed D. Al-Jawdah, Iglika G. Ivanova, Helen Waller, Neil D. Perkins, Jeremy H. Lakey and Daniel T. Peters ${ }^{*}$ (D)

\begin{abstract}
Background: Thermal regulation of gene expression occurs in many microorganisms, and is mediated via several typical mechanisms. Yersinia pestis is the causative agent of the plague and spreads by zoonotic transfer from fleas to mammalian blood with a concomitant rapid temperature change, from ambient to $37^{\circ} \mathrm{C}$, which induces the expression of capsular antigen (Caf1) that inhibits phagocytosis. Caf1 is formed into long polymeric fimbriae by a periplasmic chaperone (Caf1M) and outer membrane usher (Caf1A). All three are encoded on an operon regulated by an AraC-type transcription factor Caf1R. The aim of this study was to determine the role of Caf1R in the thermal control of caf1 operon gene expression.

Results: PCR analysis of CDNA demonstrated that the genes of the operon are transcribed as a single polycistronic mRNA. Bioinformatic analysis, supported by deletion mutagenesis, then revealed a region containing the promoter of this polycistronic transcript that was critical for Caf1 protein expression. Caf1R was found to be essential for Caf1 protein production. Finally, RT-PCR analysis and western blot experiments showed large, Caf1R dependent increases in caf1 operon transcripts upon a shift in temperature from $25^{\circ} \mathrm{C}$ to $35^{\circ} \mathrm{C}$.

Conclusions: The results show that thermal control of Caf1 polymer production is established at the transcriptional level, in a Caf1R dependent manner. This gives us new insights into how a virulent pathogen evades destruction by the immune system by detecting and responding to environmental changes.
\end{abstract}

Keywords: Gene expression regulation, Yersinia pestis, AraC transcription factor, Temperature, Fimbriae, bacterial

\section{Background}

Temperature is an important stimulus for pathogens infecting mammalian and avian hosts, allowing them to differentiate between host and non-host environments. Microorganisms can employ a suite of different mechanisms to sense and respond to changes in temperature by altering their patterns of gene expression. These mechanisms can act at either the transcriptional or translational levels and can be mediated by protein, RNA or DNA [1]. Typical mechanisms include changes in the degree of supercoiling in DNA, as well as elements of local structure such as promoter curvature, which can affect transcription efficiency, when temperature increases or falls [1]. Another common

\footnotetext{
* Correspondence: daniel.peters@ncl.ac.uk

Institute for Cell and Molecular Biosciences, Medical School, Newcastle University, Newcastle upon Tyne, UK
}

mechanism involves RNA "thermometers" that form temperature dependent mRNA secondary structures that can inhibit translation below a critical temperature [1, 2]. In addition, some proteins can undergo conformational changes in response to alterations in temperature, resulting in the post-translational modification of downstream transcription factors [3, 4], inhibition of DNA binding [5, 6], or protein degradation [7], with subsequent changes in gene expression.

The bacterium Yersinia pestis is the etiologic agent of the plague, responsible for approximately 200 million deaths across the course of three major epidemics throughout history [8], with modern outbreaks still occurring, most recently in Madagascar [9]. One of the factors responsible for the virulence of this organism is its ability to avoid phagocytosis by macrophages [10]. This ability is dependent upon a gel-like capsule, composed of polymers of the capsular antigen fraction 1 
(Caf1) protein, which coats the bacterium and is thought to act by preventing adhesin-receptor interactions. Deletion of the capsule causes an increase in the uptake of $Y$. pestis bacilli by macrophages [10] showing Caf1 to be an important protection against the host's immune system.

Caf1 forms very long, thin polymers consisting of repeating $\sim 15 \mathrm{kDa}$ subunits with polymer lengths of up to $1.5 \mu \mathrm{m}$ having been observed [11]. The polymers are highly flexible, appearing at high magnifications like beads on a string. Their biogenesis proceeds via the chaperone-usher (CU) pathway, which is employed for the production of a range of pilus structures in Gram negative bacteria [12]. Briefly, nascent, unfolded Caf1 subunits are exported to the periplasm, where they are bound by the chaperone protein Caf1M. This partially stabilises the Ig-like fold of the Caf1 subunit, before it is delivered to the usher protein, Caf1A, which resides in the outer membrane. Caf1A assembles the Caf1 subunits into a polymer that it exports to the cell surface [12] where it appears as a diffuse "flocculent" layer above the pellet in centrifuged cultures $[13,14]$. The molecular basis for the polymerisation is the donation of the $\mathrm{N}$-terminal $\beta$ strand of one subunit into the acceptor cleft of the preceding subunit in the polymer, displacing the chaperone and stably completing the subunit fold [15]. This process, known as donor-strand complementation, results in a highly stable, non-covalent polymer [16].

In $Y$. pestis, Caf1 is expressed from the caf1 operon present on the pMT plasmid [17]. Upstream of the caf $1 M$, caf $1 A$ and caf1 genes of the cafl operon is a fourth gene, caf1R, which is encoded on the opposite DNA strand. The domain structure of the Caf1R protein is that of a Rob-like AraC family transcription factor [18], consisting of a recognisable N-terminal helix-turn-helix DNA binding domain but with a distinctive C-terminal domain of unknown function. Although a putative promoter site and regulatory elements have been predicted upstream of caflM [19], their presence has yet to be empirically determined.

$Y$. pestis becomes vulnerable to macrophage attack when it is injected into the mammalian host via a flea bite. The bacterium senses this event through a range of molecular mechanisms that perceive the temperature of its environment and exploit the temperature difference between the flea (on the hosts surface $\sim 25^{\circ} \mathrm{C}$ ) and blood $\left(\sim 37^{\circ} \mathrm{C}\right)$ [8]. Caf1 protein expression is induced at $37^{\circ} \mathrm{C}$ $[8,10,20]$, allowing the bacteria to rapidly produce this protein when most at risk of being phagocytosed. Temperature dependent increases in cafl operon gene transcription have been reported $[20,21]$ but whether Caf1R plays a role in coordinating the correct temperature dependent expression is not clear.
A previous report has described the Caf1R protein as a positive transcriptional regulator [22]. There are three arguments in favour of this designation: first, a plasmid containing only the $81 \mathrm{~N}$-terminal residue helix-turn-helix DNA binding domain of Caf1R caused an increase in Caf1 production [22, 23]; second, inducing frame-shift mutations into Caf1R prevented Caf1 biogenesis; and finally, Caf1R displays homology with the AraC family of positive transcriptional regulators [22]. However, a link between Caf1R and the thermal switch has not been demonstrated.

Here, we determine the role of Caf1R in the thermosensitive control of gene expression from the caf1 operon. We show that the caf1M, caflA and caf1 genes are transcribed as a single polycistronic transcript and identify the promoter region that is critical for their transcription. Deletion of caflR completely abrogated Caf1 polymer expression, which was restored by complementing this deletion with caf $1 R$ on a second plasmid. Finally, RT-PCR and western blot experiments showed caf1 operon transcripts are substantially upregulated upon a switch from $25^{\circ} \mathrm{C}$ to $35^{\circ} \mathrm{C}$ in a Caf1R dependent manner. Therefore, we propose that the temperature induced expression of Caf1 polymers is governed at the transcriptional level in a Caf1R dependent manner, thus revealing Caf1R to be a key factor in the determination of $Y$. pestis virulence.

\section{Results}

\section{The caf1 operon is transcribed as a polycistronic transcript}

In the caf1 operon, the caf1R coding sequence is on the opposite strand to, and separated by a $328 \mathrm{nu}$ cleotide (nt) intergenic region $\mathrm{I}$, from the remaining genes, which are arranged with a very short (24nt) intergenic region II between caf1M and caflA and a larger intergenic region III of $80 \mathrm{nt}$ between caflA and caf1 (Fig. 1a). To characterise the expression of caf1 genes within the caf1 operon, PCR analysis of the RNA transcripts was employed. Cultures of $E$. coli transformed with a plasmid containing the caf1 operon (pCaf1OPeron, pCOP, Additional file 1: Table S1) or the operon preceded by an upstream T7 promoter from the vector (pT7-COP, Additional file 1: Table S1), were grown from single colonies for $16 \mathrm{~h}$ at $35^{\circ} \mathrm{C}$ to stimulate Caf1 production, following which total RNA was extracted and used to synthesise cDNA. To assess whether the caf1 genes are expressed as part of a polycistronic transcript, the cDNA was used as a template, with primers complementary to the coding regions either side of the intergenic regions (Additional file 1: Figure S1). Therefore, if the genes are expressed on a large 

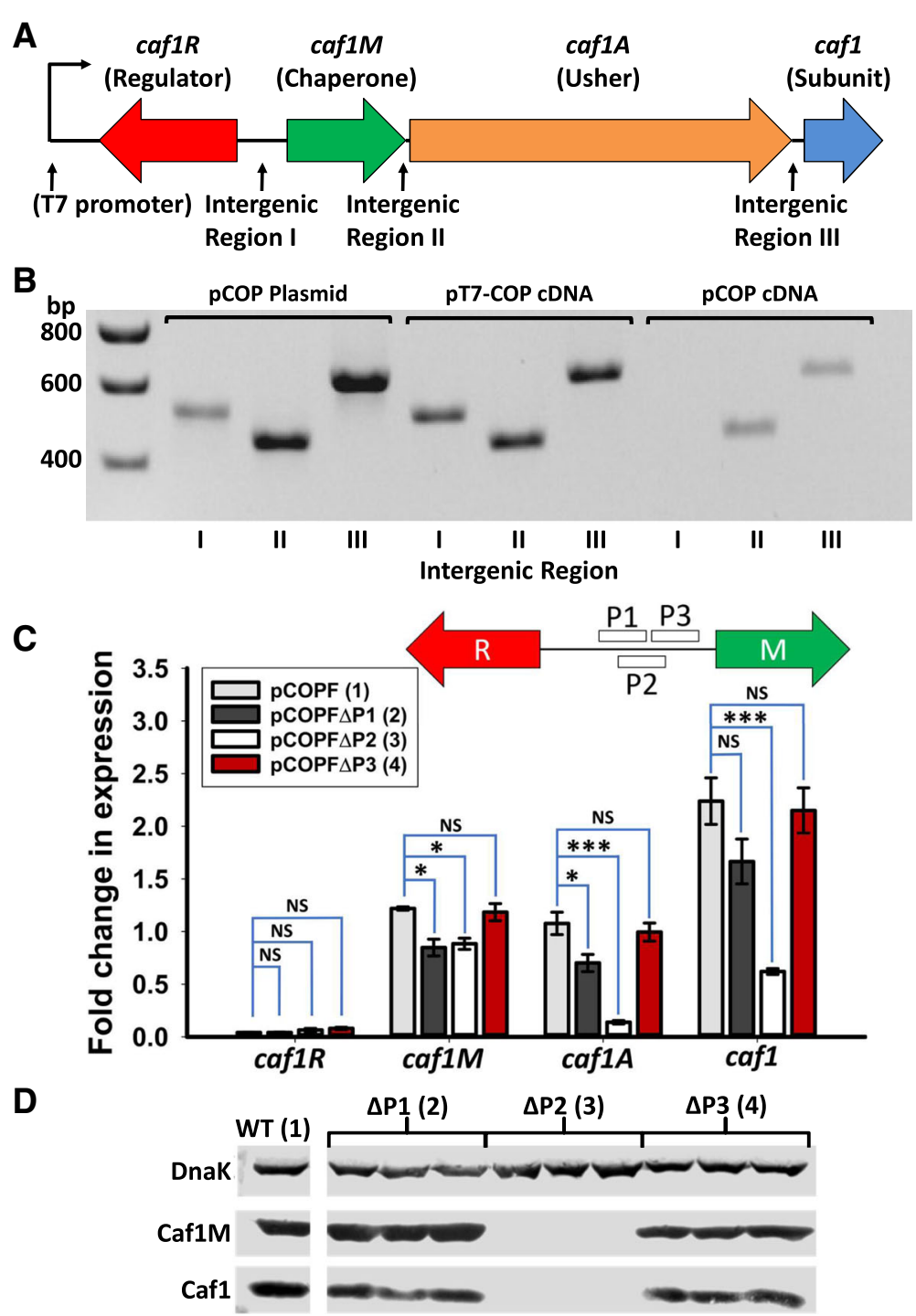

Fig. 1 Determination of cafl transcript size and promoter site. a Organisation of the cafl operon. The position of the T7 promoter, found in the artificial pT7-COP plasmid is highlighted. $\mathbf{b}$ Agarose gel showing the PCR amplification products corresponding to the three intergenic regions of the caf1 operon generated from either the PCOP plasmid, or CDNA made using mRNA from cultures of E. coli transformed with pT7-COP or pCOP plasmids and grown at $35^{\circ} \mathrm{C}$ for $16 \mathrm{~h}$. Both plasmids contain the caf1 operon as shown in (a). c Transcript levels of the caf1 operon genes as determined by RT-PCR, from cultures grown for $16 \mathrm{~h}$ of $E$. coli transformed with either pCOPF (full caf1 operon, Caf1R,M and A have FLAG tags), or pCOPF with the proposed promoter regions P1,2 or 3 deleted. Three cultures of each condition were grown, with RT-PCR reactions run in duplicate for each culture. Bar heights correspond to mean fold-change in expression relative to $\beta$-lactamase. Error bars represent standard error of the mean (S.E.M) from three biological replicates. Asterisks represent significant differences between groups $\left({ }^{*}-P<0.05,{ }^{* *}-P<0.01,{ }^{* * *}\right.$ - $P<0.001$, NS - not significant, determined by ANOVA with Holm- Šidák post-hoc test). A diagram detailing the positions of the P1, 2 and 3 regions is shown in the top right of the graph. $\mathbf{d}$ Western blot of the above cultures showing the levels of Caf1M and Caf1 (detected by antiFLAG tag and anti-Caf1 antibodies respectively), and using DnaK (detected by an anti-DnaK antibody) as a loading control

transcript, amplification of the intergenic regions should proceed when the cDNA is used as a template, whereas single transcripts will result in no amplification. Amplification products could be detected from intergenic regions II and III from pCOP, showing that caflM and caflA, as well as caf1A and caf1, are co-transcribed (Fig. 1b). The intergenic region between caflM and caflA is very small ( $24 \mathrm{nt})$, and unlikely to harbour a promoter. This suggests that in the natural system, caflM, caflA and caf1 are all transcribed together on one mRNA of approx. 3900 nt. For pT7-COP, all three intergenic regions could be detected, suggesting that the T7 promoter, which is upstream of caf1R, drives transcription that proceeds through all four genes. This was of interest since we had previously found by chance that leaky expression from this T7 promoter was able to drive significant Caf1 polymer production [13]. 
Identification of the long caf1 operon transcript promoter To identify the promoter that drives transcription of this long mRNA, the DNA sequence between cafiR and cafiM (intergenic region I) was used as an input into the BPROM (Softberry Inc., Mount Kisco, NY, USA, http://www.softberry.com) [24] and Neural Network Promoter Prediction 2.2 (NNPP2.2) [25] webservers. These predictions led us to define three potential promoter regions of $41 \mathrm{bp}$ (P1, P2 and P3, Additional file 1: Figure S2) upstream of caf1M that could potentially drive the transcription of the polycistronic caf1 transcript. Interestingly, the P2 region contains the putative promoter previously predicted by Galyov et al. [23]. Each region was then separately deleted from pCOPF (in which Caf1R, $M$ and A have added C-terminal FLAG tags, Additional file 1: Table S1) and the resulting plasmids used to transform BL21(DE3) cells. To assess the effect of the deletions, protein levels after $16 \mathrm{~h}$ of growth at $37^{\circ} \mathrm{C}$ were determined by western blot using anti-FLAG antibodies and levels of each transcript were measured by RT-PCR (Fig. 1c,d). Deletion of the P3 region showed little effect on the levels of protein or transcript. For P1, deletion had little effect on protein expression, but did appear to cause a small drop in transcript level. However, the greatest effect was seen upon deletion of the P2 region, where synthesis of all the Caf1 proteins was completely abrogated, accompanied by a substantial decrease in caf1A and caf1 transcript levels. The levels of caf1M transcript in the P1 and P2 deletions are both slightly reduced, but whereas Caf1M synthesis is unaffected by P1 deletion, no Caf1M protein was detected from the P2 delection. The deleted P2 region thus contains or overlaps the promoter responsible for the large, polycistronic transcript observed by PCR analysis.

\section{Caf1R regulates the caf1 operon}

To further investigate the importance of Caf1R to Caf1 polymer production, the cafiR gene was deleted from the pCOPF plasmid (pCOP $\triangle \mathrm{R}$, Additional file 1: Table S1). The $\mathrm{pCOPF}$ and $\mathrm{pCOP} \triangle \mathrm{R}$ plasmids were transformed into BL21(DE3) E. coli cells and expression cultures were grown from single colonies at $35^{\circ} \mathrm{C}$. Expression of Caf1 polymers correlates with the appearance of a flocculent layer that sits on top of the cell pellet in centrifuged expression cultures $[13,14]$. Expression cultures were assayed for flocculent layer production, which directly corresponded to the amount of Caf1 polymer secreted by the bacteria (Additional file 1: Figure S3). The caf1R deletion completely abolished Caf1 protein production from the $\mathrm{PCOP} \Delta \mathrm{R}$ plasmid, with no flocculent layer observed and no Caf1 protein detectable in the pellet by western blot (Fig. 2), demonstrating that caf1R is necessary for Caf1 production.

pCOPF $\triangle \mathrm{R}$ was then co-transformed into BL21(DE3) cells with pBad-Caf1R (Additional file 1: Table S1),

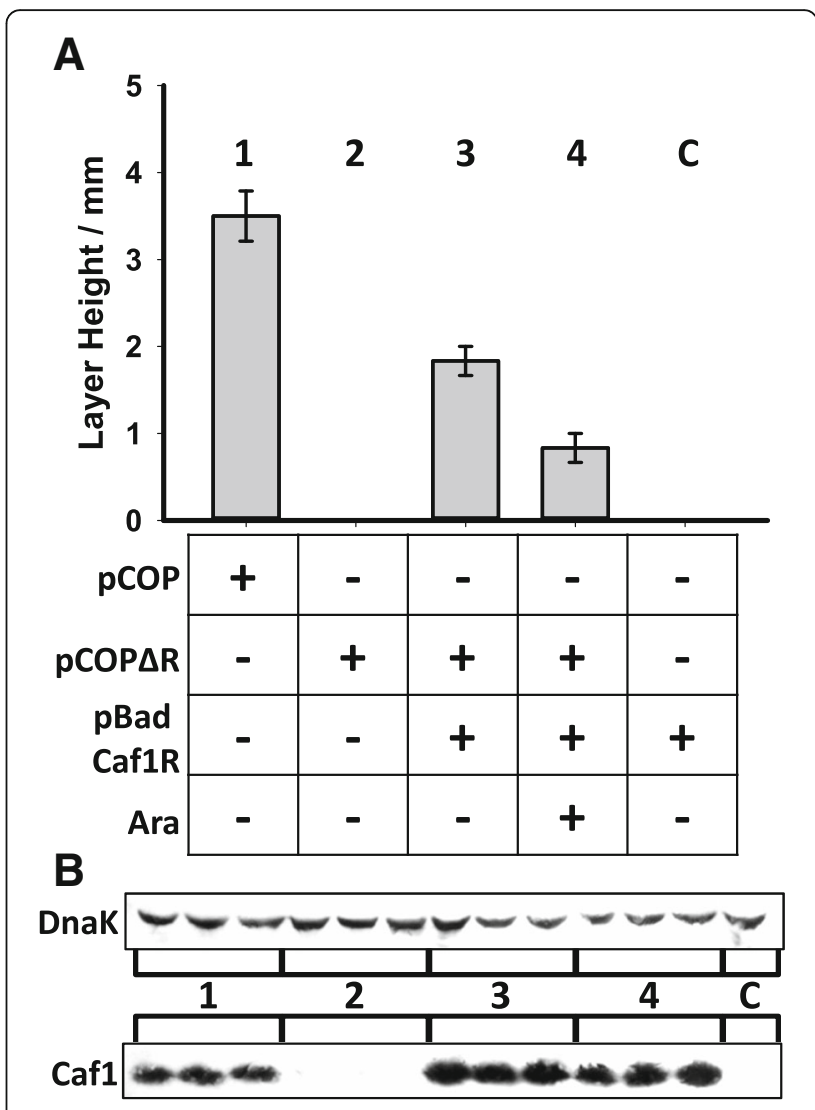

Fig. 2 Caf1 protein production is dependent upon low levels of Caf1R. a Graph of the flocculent layer height obtained from $E$. coli cultures containing either pCOP (full cafl operon, 1), pCOP $\triangle \mathrm{R}$ (caf1 operon lacking Caf1R, 2), a co-transformation of pCOP $\Delta R$ and pBad Caf1R (arabinose inducible Caf1R) without (3) and with (4) $0.005 \% \mathrm{~W} / \mathrm{V}$ arabinose added to the culture, and pBad Caf1R only control (C). Cultures were grown for $16 \mathrm{~h}$ at $35^{\circ} \mathrm{C}$. Bar heights correspond to the mean flocculent layer height obtained from three separate cultures where error bars represent the standard error of the mean (S.E.M). $\mathbf{b}$ Western blot of three separate cell pellets from the above cultures, probed with an anti-Caf1 antibody. DnaK was used as a loading control, probed with an anti-DnaK antibody

where caf1R is under the control of an arabinose inducible promoter. Complementing $\mathrm{pCOPF} \triangle \mathrm{R}$ with pBad-Caf1R in the absence of arabinose rescued Caf1 protein expression (Fig. 2). Induction of Caf1R from the pBad Caf1R by the addition of arabinose also rescued Caf1 protein expression, although the height of the flocculent layer was lower in this case suggesting that only very low levels of Caf1R are needed to promote Caf1 protein expression, and that higher levels are inhibitory to Caf1 biogenesis. These results show that Caf1R is essential for Caf1 production.

Temperature induction of caf1 operon expression occurs at the transcriptional level

It is useful for $Y$. pestis to control the formation of the Caf1 polymer using temperature in order to provide 
immediate protection from macrophages upon transfer to a warm blooded host. The increase in caf1 operon expression with temperature has been demonstrated previously $[8,20,21]$, but the underlying molecular mechanism has not been investigated. Therefore, we tested the hypothesis that the Caf1R protein is the transcription factor that mediates the thermoregulation of Caf1 expression.

To assess this claim, E. coli were transformed with pCOPF or pCOPF $\triangle \mathrm{R}$ and grown for $16 \mathrm{~h}$ at $25^{\circ} \mathrm{C}$, such that caf1 is not expressed. The stationary phase cultures were then diluted to $0.5 \mathrm{OD}_{600}$ and then grown for one further hour at either $25^{\circ} \mathrm{C}$ or $35^{\circ} \mathrm{C}$. Transcriptional levels of the caf1 operon genes were then examined through RT-PCR. A large, significant increase in the relative transcript levels of caf $1 M$, caf1A and caf1 could be seen at $35^{\circ} \mathrm{C}$ compared to $25^{\circ} \mathrm{C}$ for cells transformed with pCOP, with fold increases of 23.3, 33.4 and 26.7 respectively (Fig. 3a). An 8.8 fold increase in caf1R transcript levels was also observed, but this was not statistically significantly different from the levels observed at $25^{\circ} \mathrm{C}$. Crucially, in the absence of Caf1R, no temperature dependent increase was seen (Fig. 3b), showing that the increase in transcription levels was not a general effect of temperature change. Additionally, the overall level of transcript produced from $\mathrm{PCOPF} \triangle \mathrm{R}$ was significantly lower in all cases when compared to the system containing all four genes, again highlighting the influence of Caf1R.

The effect of the temperature change was then analysed at the translational level by performing western blot experiments on the same cultures used for RT-PCR. The levels of protein detected matched the RT-PCR data, where levels of Caf1M and Caf1 protein could be seen to increase upon incubation at the higher temperature relative to the lower temperature, while being completely undetectable in the absence of Caf1R (Fig. 3). Caf1A, a large membrane protein, was not visualised by western blot. Similarly, although Caf1R is soluble and of a similar size to the easily detected Caf1M, it was also not detected by anti-FLAG western blot, presumably in this case because its concentration was consistently below the limit of detection. This is not surprising, as transcription factors are often present in very low amounts in bacterial cells $[26,27]$, and our data show that even the low levels of expression from the uninduced, tightly regulated $\mathrm{P}_{\mathrm{BAD}}$ promoter [28] are enough to rescue Caf1R deletion (Fig. 2).

When E. coli transformed with the pT7-COP plasmid were grown at $30{ }^{\circ} \mathrm{C}$ (where the natural Caf1R system is switched off and transcription is driven by the T7 promoter), high levels of Caf1 expression could still be detected (Fig. 4). The T7 promoter appears to be stronger than the natural cafiR promoter, since it generates a

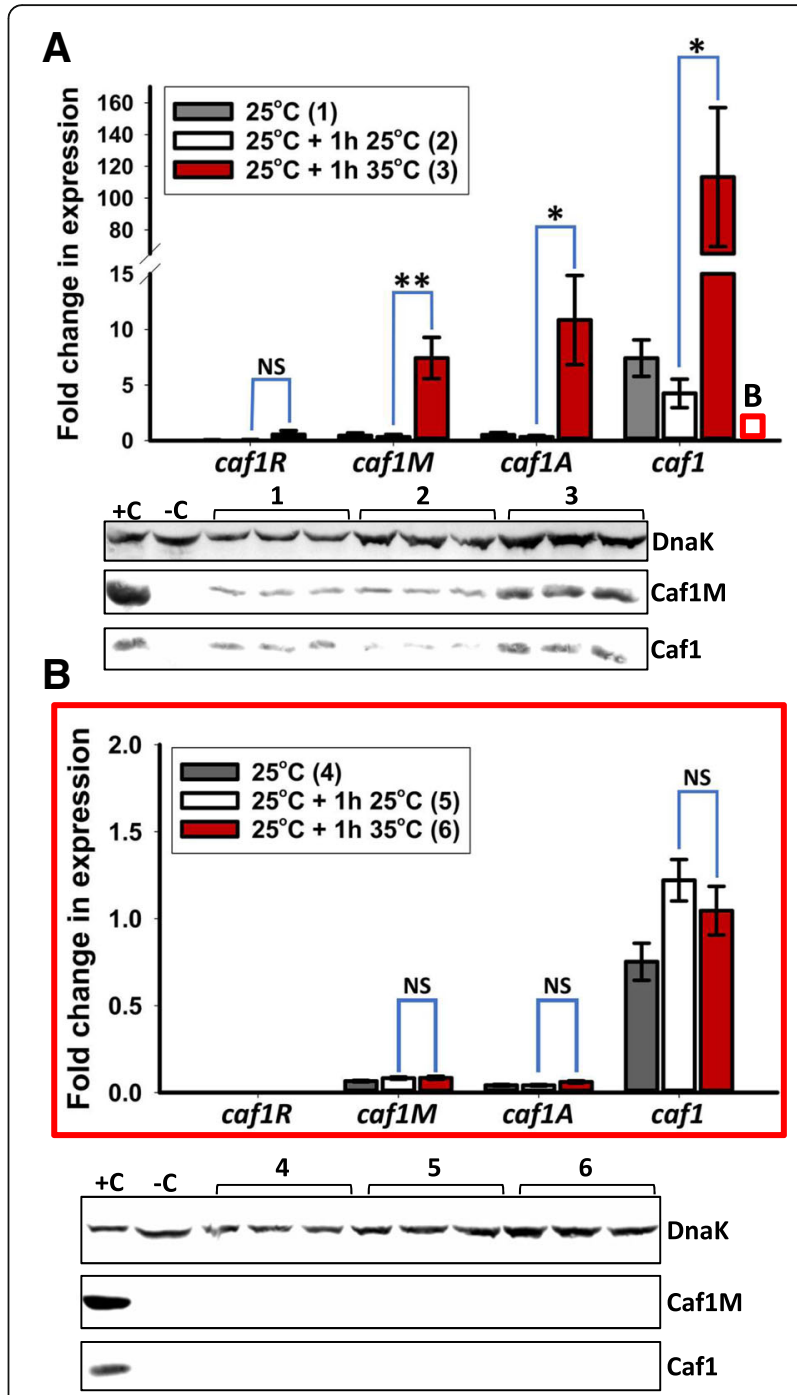

Fig. 3 caf1 operon gene expression is temperature and Caf1R dependent. Transcript levels, determined by RT-PCR, of each caf1 gene are shown for cultures of E. coli transformed with PCOPF (full caf1 operon, (a)) and pCOPF $\triangle \mathrm{R}$ (caf1 operon, Caf1R deleted, (b)), grown at $25^{\circ} \mathrm{C}$ overnight $(\sim 16 \mathrm{~h})$, then either $25^{\circ} \mathrm{C}$ or $35^{\circ} \mathrm{C}$ for 1 further hour. The red box in a shows the approximate scale of the Y-axis in $\mathbf{b}$. Three cultures of each condition were grown, with RT$P C R$ reactions run in duplicate for each culture. Bar heights correspond to mean fold-change in expression relative to $\beta$ lactamase. Error bars represent standard error of the mean (S.E.M) from three biological replicates. Asterisks represent significant differences between groups $\left({ }^{*}-P<0.05\right.$, ${ }^{* *}-P<0.01$, ${ }^{* *}-P<0.001$, NS - not significant, determined by ANOVA with Holm- Šidák posthoc test). Western blots showing the levels of Caf1M and Caf1 (detected by anti-FLAG tag and anti-Caf1 antibodies respectively) in the cell pellets of the expression cultures are displayed underneath each graph, using DnaK probed with an anti-DnaK antibody as a loading control. $+C$ and $-C$ represent the pellets of BL21(DE3) cells transformed with pCOPF and untransformed respectively, and grown for $16 \mathrm{~h}$ at $35^{\circ} \mathrm{C}$ 
greater amount of flocculent layer. Differences in flocculent height for pT7-COP containing cells are likely due to differences in the efficiency of $\mathrm{T} 7$ transcription between the two temperatures [29], and also the thermal activation of caf1 operon transcription from the native promoter at $35^{\circ} \mathrm{C}$. The relative thermal independence of the T7 driven expression implies that the temperature regulation of the caf1 operon takes place primarily at the transcriptional level, with post-transcriptional (translational and post-translational) regulation having very little, if any, role.

\section{Discussion}

\section{caf1 operon genes are expressed from a polycistronic transcript}

The results of this study show that the caf1 operon is expressed as a long, polycistronic transcript from a promoter that resides in the $\mathrm{P} 2$ region in a Caf1R dependent manner. Previously, Galyov et al. predicted the presence of regulatory regions and a putative promoter that would drive caf1M transcription, and identified a Shine-Dalgarno sequence 7 bases upstream of the Caf1M start codon [23]. We used an independent

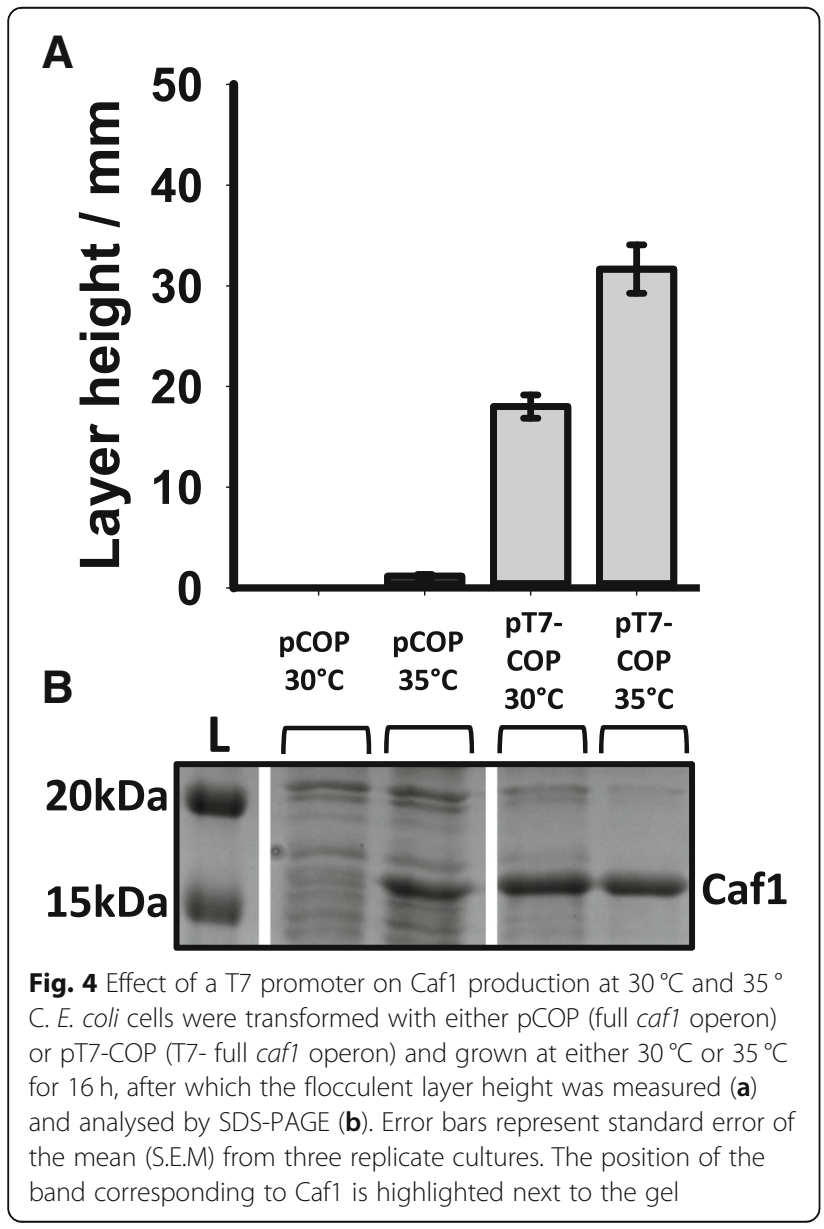

software tool that identified potential promoter regions that could transcribe the polycistronic caf1 operon transcript, before confirming their activity through deletion mutagenesis and RT-PCR. The putative promoter predicted by Galyov et al. overlaps with the P2 region we identify here as being essential for the expression of the operon. Therefore, we have independently identified and experimentally confirmed the presence of the promoter responsible for transcription of the caf1 operon.

Considering caflM, caflA and caf 1 are transcribed as a single polycistronic transcript, it was surprising that the RT-PCR results showed that each of the genes has a particular transcriptional level, where the levels of cafiM and caf $1 A$ transcripts were similar and caf1 transcript much higher. There are two potential explanations of this: either the caf1 gene can be transcribed by a second, Caf1R responsive promoter, or the translational units within the polycistronic RNA transcript have different levels of mRNA stability. We used 5' RACE (Rapid Amplification of cDNA Ends) to search for a second promoter upstream of the caf1 gene. If a promoter exists in this region, the majority of transcript sequences should terminate inside intergenic region III at the transcriptional start site (Additional file 1: Figure S4), but 7 out of 8 sequences obtained continued through the intergenic region into caf1A (Additional file 1: Figure S5), thus corresponding to the observed polycistronic transcript. These sequences terminated at different locations, implying the termination is due to dissociation of the polymerase enzyme rather than a transcriptional start site within this region of caflA. Moreover, deletion of the P2 region, which lies upstream of caf1M and is therefore responsible for transcription of the polycistronic transcript, abolished the expression of all caf1 genes. If separate promoters were present for each gene, this deletion would have a substantially reduced effect on caf $1 A$ and caf1 expression. A previous study by Galyov et al. [19] predicted the presence of a putative promoter upstream of cafl, at the $3^{\prime}$ end of the caf $1 A$ gene. However, in isolation this region did not enable caf1 expression [19], suggesting that it does not contain a functional promoter, in concordance with our results.

As a second promoter could not be detected, the differential stability of the translational units within the mRNA, such as has been previously reported [30], is a more plausible explanation for the differing levels of transcript observed in the RT-PCR experiments. Upon a shift of the bacteria to $35^{\circ} \mathrm{C}$, such a system would allow Caf1R to activate the transcription of the caf1 operon polycistronic mRNA, which would then be degraded to different degrees resulting in differential levels of transcript for caf1M, caflA and caf1. To produce long Caf1 polymers, a large number of subunits is required, with fewer chaperones and ushers necessary. Therefore, this 
system appears to allow cells to produce the optimal levels of each protein from a single transcript.

\section{Thermosensitive transcriptional regulation of the caf1 operon}

The ability to regulate gene expression in response to changes in temperature is important for $Y$. pestis, which lives mainly in two environments with different ambient temperatures: the flea at $\sim 25^{\circ} \mathrm{C}$ [8], and mammals, with body temperatures of around $37^{\circ} \mathrm{C}$. This difference in temperature is therefore a simple signal that allows the bacterium to determine whether it is in the vector or the host where it behaves as a mammal pathogen, expressing factors related to virulence and immunoevasion. The results of the temperature switching experiment clearly show the rapid upregulation of the expression of caf1M, caf1A and caf1 upon an increase in temperature. The fold increase in transcript levels with temperature, that we observe, correlates well with those previously described [20] for caf1R and caf1M (8.8 vs 8.9 fold and 23.3 vs 19.7 fold respectively), but we detect greater increases in transcription for caf1A and caf1 (33.4 vs 9.7 fold and 26.7 vs 7.8 fold respectively). Crucially, this upregulation occurs at the transcriptional level, and is wholly Caf1R dependent.

The difference in transcriptional output is sufficient to describe the observed temperature sensitivity of Caf1 protein production. Not only did the levels of Caf1M and Caf1 observed by western blot correlate with the levels of transcript seen by RT-PCR but bypass of transcriptional regulation through the introduction of a T7 promoter permitted expression of Caf1 at $30^{\circ} \mathrm{C}$, when there was no expression from the native caf1 operon under these conditions. If a method of translational or post-translational regulation was present (e.g. a riboswitch), then it would be expected that these mechanisms would regulate $\mathrm{T} 7$ driven caf1 expression at lower temperatures. Therefore, these mechanisms are either not present, or have a very weak effect in the Caf1 system. Caf1R mediated transcriptional control is thus the main mechanism to express Caf1 polymers under the appropriate conditions.

\section{Caf1R mediates thermal regulation}

It is clear from our results that Caf1R is the element that transduces the temperature change into a transcriptional response. There are three models through which this could take place (Fig. 5). In model A (Fig. 5a), the Caf1R protein itself is the thermoresponsive element. At $25{ }^{\circ} \mathrm{C}$ the protein is either unable to bind DNA, or unable to stimulate transcription of the caf1 operon. Upon a shift in temperature to $35^{\circ} \mathrm{C}$, the protein changes conformation, becoming active and inducing transcription of the caf1 operon. In model B (Fig. 5b), the thermoresponsive

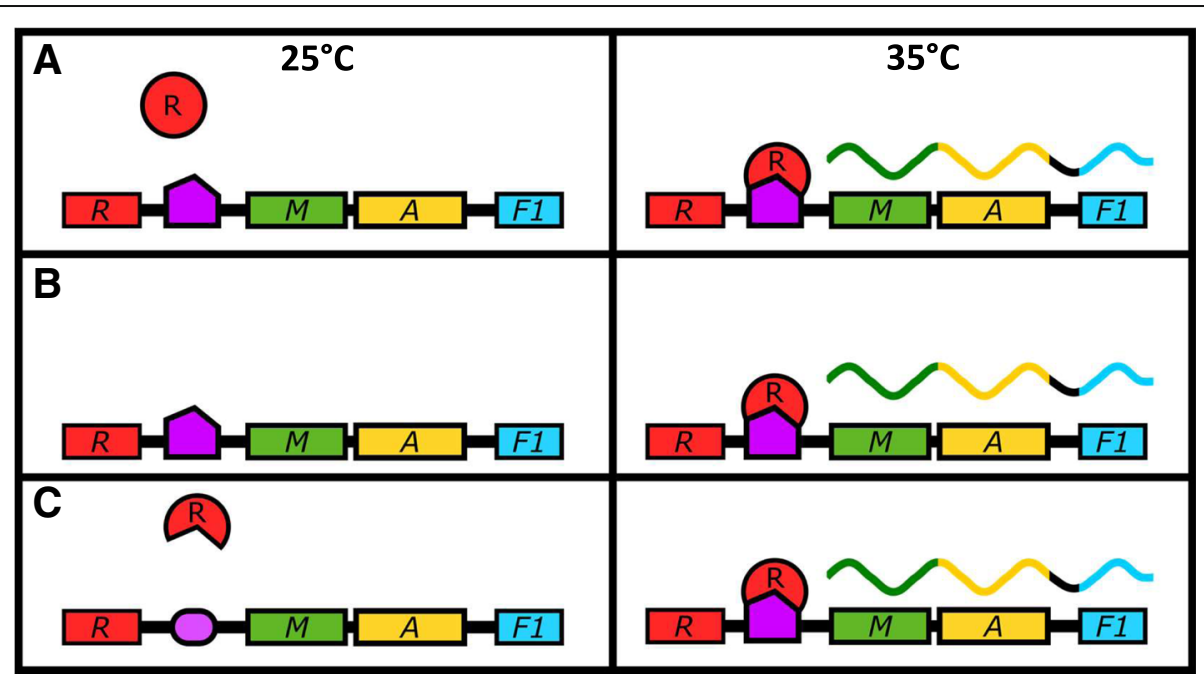

Fig. 5 Models of thermoresponsive Caf1R-dependent transcriptional control of gene expression. Three models that potentially describe the Caf1R dependent thermoresponsive increase in caf1 operon transcription are shown, with their states at $25^{\circ} \mathrm{C}$ and $35^{\circ} \mathrm{C}$ depicted in the left and right hand side panels respectively. In model (a), the Caf1R protein is the thermoresponsive element. At $25^{\circ} \mathrm{C}$ it is unable to activate transcription of the caf1 operon, regardless of its DNA binding state. At $35^{\circ} \mathrm{C}$, a conformational change allows the protein to activate transcription. Inactive Caf1R is shown as a red circle and active Caf1R as a red arc. In (b), the Caf1R protein abundance is thermoresponsive. Transcription is not thermally regulated so either Caf1R is always transcribed but only translated at $35^{\circ} \mathrm{C}$ or Caf1R is stabilised at $35^{\circ} \mathrm{C}$. The increased Caf1R protein level activates transcription of the operon. In (c), the DNA is the thermoresponsive element. At $25^{\circ} \mathrm{C}$, the DNA is not in an optimal conformation for Caf1R binding, and so transcription is not activated. At $35^{\circ} \mathrm{C}$, a change in the DNA facilitates optimal Caf1R binding, and so transcription of the operon is activated. Genes are shown as coloured rectangles (red, green, yellow and blue for caf1R, caf1M, caf1A and caf1 respectively), with the Caf1R DNA binding site shown in purple. mRNA transcripts are represented as wavy lines coloured according to the gene they are transcribed from 
element is the level of Caf1R, mediated either through temperature dependent increase in caflR translation or decrease in Caf1 R protein turnover. Finally, in model $C$ (Fig. 5c), a temperature dependent structural change in a DNA regulatory region, e.g. supercoiling or promoter topology [1] is recognised by Caf1R, which binds and activates transcription.

Well studied examples found in Yersinia show how transcription factors can be thermally regulated in very different ways. In one case LcrF, which controls Type III secretion systems (TTSS) involved in phagocytosis evasion, undergoes translational control through the use of an RNA thermometer in which ribosome binding to the LcrF mRNA is inhibited by a temperature sensitive RNA secondary structure [2]. In contrast, the RovA transcription factor is itself a proteinaceous thermosensor. RovA functions as a "global regulator" of transcription in response to increases in temperature, resulting in the expression of the TTSS and Yop effector proteins in $Y$. pestis, and the internalization factor invasin in $Y$. pseudotuberculosis [31]. The mechanism through which RovA senses temperature involves a flexible loop situated between two alpha helices that have a role in dimer formation [7]. Upon temperature increase, the protein partially unfolds, lowering its affinity towards DNA and increasing its susceptibility to proteases, thus de-repressing the transcription of target genes.

The closest homologue of Caf1R is the Rob protein of E. coli [18], which consists of an N-terminal DNA binding domain coupled to a C-terminal GyrI-like domain [32]. Rob acts as a transcriptional activator that is induced by dipyridyl or decanoate [33]. In the uninduced state, the C-terminal domain causes sequestration of Rob into distinct cellular foci, preventing it from interacting with DNA and activating transcription. Addition of the inducer allows Rob to disperse through the cell and activate the transcription of its target genes [33] though direct interactions between its $\mathrm{N}$-terminal domain and the $\sigma^{70}$ subunit of RNA polymerase [34]. Truncated Rob proteins, where the GyrI domains were absent, were able to activate transcription in the absence of inducer [33, 35]. Additionally, MarA, which is homologous to the $\mathrm{N}$-terminal DNA binding domain of Caf1R, contains no C-terminal domain, and so regulates transcription on the basis of its abundance rather than the presence of an inducer $[33,36]$. A truncated Caf1R protein, containing only the first 82 amino acids of the DNA binding domain, was seen to allow expression of Caf1, whereas complete Caf1R knockout prevents Caf1 expression [22, 23]. The homology of Caf1R to these proteins therefore suggests that its $\mathrm{N}$-terminal DNA binding domain is responsible for binding DNA and activating transcription, whilst the C-terminal GyrI-like domain is responsible for the characteristic Caf1R behaviour. Whether this is due to changes in Caf1R conformation (model A) or abundance (model B) we cannot resolve. Additionally, model $\mathrm{C}$ would also account for the results we describe here and Karlyshev et al. observed a series of repeated DNA sequences within intergenic region I which may interact with Caf1R and orient the DNA for optimal induction of gene expression [22]. It is also possible that a combination of these models is responsible. We made numerous attempts to purify sufficient amounts of Caf1R for such studies, but it appeared to be particularly unstable. Therefore, efforts to produce a soluble, functional construct will likely be necessary in order to answer these questions.

\section{Thermosensitive transcriptional activators in Gram- negative bacterial pathogens}

The function of Caf1R revealed in this study is of interest due to its role in the immunoevasive ability of a highly dangerous pathogen. However, it is possible that Caf1R also represents a class of transcription factors that has received little prior study. PSI-BLAST searches reveal that the most similar proteins to Caf1R are unannotated sequences from various Gram-negative bacteria such as E. coli and several Salmonella species. However, one similar protein sequence is LdaA from an enteropathogenic $E$. coli strain (EPEC). LdaA is a putative regulatory protein that exists as part of the $l d a$ locus, named locus of diffuse adherence for its apparent ability to attenuate the adherence of E. coli to HEp-2 cells [37]. The lda gene displays sequence similarity with other fimbrial proteins, particularly the K88 Fae proteins, but unlike these structured fimbriae, Lda fibres appear flexible when visualized by electron microscopy. These data, as well as the similarity of LdaE to known periplasmic chaperones [37], hint that the Lda proteins may assemble in a manner similar to Caf1, and form a similar structure. If this is the case, the sequence similarity of LdaA and Caf1R suggests it may potentially function in an analogous way. Additionally, homology between Caf1R and AfrR, a putative transcription factor in the AF/R1 operon, has been identified previously [38]. The AF/R1 pilus produced by the genes of this operon plays an important role in the adhesion and pathogenicity of a rabbit diarrheagenic E. coli (RDEC) strain. If these proteins indeed function in a similar way to Caf1R, it may be evidence of a conserved system of thermosensitive transcriptional activation present in Gram-negative pathogens.

\section{Conclusion}

Thermosensitive expression of the caf1 operon is determined on the transcriptional level in a Caf1R 
dependent manner. The caf1 operon genes caf1M, caf1A and caf1 are transcribed as a single polycistronic mRNA, from a promoter within the P2 region upstream of caf1M. The transcription of this mRNA is substantially upregulated upon a temperature shift from $25^{\circ} \mathrm{C}$ to $35^{\circ} \mathrm{C}$. This is sufficient to allow protein expression and the subsequent formation of Caf1 polymers. As Caf1 has a key role in allowing $Y$. pestis bacteria to evade phagocytosis, these results reveal a simple but important mechanism through which a dangerous pathogen can sense and respond to its environment.

\section{Methods}

\section{Plasmids and cell culture}

Plasmid constructs (Additional file 1: Table S1) were derived from pGEM-T Caf1 and pBad33SD Caf1, described previously [13]. pCOP was constructed by substitution of the T7 promoter with a random sequence of the same length using a Q5 Site-directed mutagenesis kit (New England Biolabs). All other plasmids were constructed using an In-Fusion HD cloning kit (Clontech). Deletions were made by omitting the relevant region of the plasmid from the amplified region, then ligating the amplified region back together. Primers sequences are shown in Additional file 1: Table S2.

Transformations were performed using E. coli BL21 (DE3) (New England Biolabs). Three different colonies were selected from each plate and grown in LB media overnight at $37^{\circ} \mathrm{C}, 180 \mathrm{rpm}$. Glycerol stocks were prepared for all transformed bacteria using $500 \mu \mathrm{l}$ of bacterial culture and $500 \mu \mathrm{l}$ of $60 \%(\mathrm{v} / \mathrm{v})$ glycerol solution. Expression cultures were prepared using $5 \mathrm{ml}$ TB media containing $100 \mu \mathrm{g} \mathrm{ml}^{-1}$ ampicillin and/or $20 \mu \mathrm{g} \mathrm{ml}^{-1}$ chloramphenicol and were inoculated using a stab from one of the glycerol stocks. To induce expression from pBad plasmids, L-arabinose was added at the concentrations described in the text at the same time as the cultures were inoculated. The flocculent layer heights were measured using a ruler after the centrifugation of capillary tubes containing Caf1 expression cultures at $2367 \mathrm{x}$ g, $22^{\circ} \mathrm{C}$ for $15 \mathrm{~min}$.

For analysis of caf1 operon transcript levels, bacterial cells were cultured in triplicate from glycerol stocks of E. coli BL21 (DE3) cells transformed with pCOPF (Additional file 1: Table S1) and grown at $25^{\circ} \mathrm{C}$ overnight. The $\mathrm{OD}_{600}$ was measured for all cultures and then $2 \mathrm{ml}$ were taken from each culture to be analysed by RT-PCR and western blot. The remaining cultures were diluted to an $\mathrm{OD}_{600}$ of 0.5 and then each culture was split into two cultures: one to be incubated at $25^{\circ} \mathrm{C}$ and the other simultaneously at $35^{\circ} \mathrm{C}$. After one hour incubation the $\mathrm{OD}_{600}$ was measured and $2 \mathrm{ml}$ samples taken from each culture for RT-PCR and western blot analysis.

\section{RNA extraction and CDNA synthesis}

RNA was isolated using an EZ-10 Total RNA Mini-Preps Kit (Bio Basic Inc.) by transferring $1 \mathrm{ml}$ from each culture $\left(\sim 2 \times 10^{9}\right.$ cells $)$ separately to be centrifuged at $10,000 \mathrm{x} \mathrm{g}$ for $1 \mathrm{~min}$. Supernatants were discarded and $100 \mu \mathrm{l}$ of lysozyme solution $\left(400 \mu \mathrm{g} \mathrm{ml}^{-1}\right.$ lysozyme in RNase-free water) added to each sample pellet. The mixtures were resuspended thoroughly and RNA extracted according to the manufacturer's protocol. The concentration of RNA was measured using a Nanodrop UV spectrophotometer (Labtech). RNA samples were then used to perform cDNA synthesis using a QuantiTect Reverse Transcription Kit (Qiagen) according to the manufacturer's protocol. The resulting concentration of cDNA was measured using a Nanodrop UV spectrophotometer and the samples stored at $-20^{\circ} \mathrm{C}$.

\section{PCR and RT-PCR}

The master reaction mix for RT-PCR experiments was prepared using GoTaq Flexi DNA Polymerase (Promega) by adding $4 \mu \mathrm{l}$ nuclease-free water, $4 \mu \mathrm{l} 5 \mathrm{X}$ Colorless GoTaq Flexi Buffer, $3 \mu \mathrm{l}$ of $2 \mathrm{mM}$ dNTPs, $3.2 \mu \mathrm{l}$ of 25 $\mathrm{mM} \mathrm{MgCl}_{2}, 0.2 \mu \mathrm{l}$ SYBR Green (Sigma, S9430) (diluted 200 times with $100 \%$ DMSO), $0.2 \mu$ l GoTaq Flexi DNA Polymerase, $0.8 \mu \mathrm{l} 10 \mu \mathrm{M}$ primer mix and $5 \mu \mathrm{l}$ of $50 \mathrm{ng}$ $\mu^{-1}$ cDNA per reaction. Samples were loaded in a Rotor-Gene Q instrument (Qiagen) and critical threshold cycle values (CT values) were collected to measure the fold change in gene expression for each target gene, relative to $\beta$-lactamase transcription from the plasmid, with a threshold level of 0.5. Primer sequences are shown in Additional file 1: Table S2, with a schematic of the design shown in Additional file 1: Figure S1. Thermal cycling conditions are stated in Additional file 1: Table S3.

For transcript analysis, PCR was conducted using Phusion High-Fidelity DNA Polymerase kit from (New England Biolabs) by adding $10 \mu \mathrm{l}$ of $5 \mathrm{X}$ Phusion GC buffer, $1 \mu \mathrm{l}$ of $10 \mathrm{mM}$ dNTPs, $2.5 \mu \mathrm{l}$ each of $10 \mu \mathrm{M}$ forward and reverse primers, $2 \mu \mathrm{l}$ of $10 \mathrm{ng}^{-1}$ template DNA, $1.5 \mu \mathrm{l}$ of DMSO, $0.5 \mu \mathrm{l}$ of Phusion DNA polymerase and nuclease-free water up to $50 \mu$ l. Thermal cycling conditions are stated in Additional file 1: Table S4.

\section{Rapid amplification of CDNA ends (RACE)}

5' RACE experiments were performed as described previously [39] with minor modifications. Briefly, cDNA was prepared by performing the reverse transcriptase reaction using a $9 \mathrm{bp}$ long gene specific primer (Additional file 1: Table S2) complementary to a $3^{\prime}$ region of the caf1 gene. cDNA samples were diluted two times with nuclease-free water and purified using $10 \mathrm{kDa}$ molecular weight cut-off Vivaspin centrifugal concentrators 
(Sartorius) spun at $1000 \mathrm{x}$ g for $30 \mathrm{~min}$. This step was repeated to prepare the samples for poly-adenine tailing.

Poly-adenine tailing was performed by mixing $0.5 \mu \mathrm{l}$ terminal transferase enzyme (20 Units / $\mu$ l, New England Biolabs), $5 \mu \mathrm{l} 10 \mathrm{x}$ terminal transferase buffer, $5 \mu \mathrm{l}$ of 2.5 $\mathrm{mM} \mathrm{CoCl} 2,0.5 \mu \mathrm{l}$ of $10 \mathrm{mM}$ dATP for tailing, $5 \mathrm{pmol}$ of cDNA to be tailed and nuclease-free water up to $50 \mu \mathrm{l}$. The mixture was incubated at $37^{\circ} \mathrm{C}$ for $30 \mathrm{~min}$ and then heated at $70^{\circ} \mathrm{C}$ for $10 \mathrm{~min}$ to inactivate the reaction.

Tailed cDNA was then amplified by PCR. The PCR reaction was prepared by mixing $0.5 \mu \mathrm{l}$ of $2 \mathrm{U} / \mu \mathrm{l}$ Phusion DNA polymerase (New England Biolabs), $10 \mu \mathrm{l} 5$ x GC Phusion buffer, $1 \mu \mathrm{l}$ of $10 \mathrm{mM}$ dNTP mix, $1.2 \mu \mathrm{l}$ of $10 \mu \mathrm{M}(\mathrm{dT}) 17$-adapter primer (Additional file 1: Table S2), $2.5 \mu \mathrm{l}$ of $10 \mu \mathrm{M}$ adapter primer (Additional file 1: Table S2), $2.5 \mu \mathrm{l}$ of $10 \mu \mathrm{M}$ gene specific primer (Additional file 1: Table S2) and 3\% DMSO with $2 \mu \mathrm{l}$ of tailed cDNA and nuclease-free water up to $50 \mu \mathrm{l}$. Cycling conditions are stated in Additional file 1: Table S5.

The PCR product was analysed by agarose gel electrophoresis. Amplification products were extracted from the gel using a Monarch gel extraction kit (New England Biolabs) according to the manufacturer's protocol. The concentration of pure DNA was measured using a Nanodrop UV spectrophotometer (Labtech) and sequenced by Eurofins Genomics.

\section{Western blot}

Bacterial cultures were centrifuged at 20,000 x g for 5 min. Supernatants and flocculent layers were discarded and cell pellets resuspended in $100 \mu \mathrm{l}$ per $\mathrm{OD}_{600}$ of 100 $\mathrm{mM}$ DTT, $2 \% w / v$ SDS. The samples were heated at $95^{\circ}$ $\mathrm{C}$ for $10 \mathrm{~min}$ and centrifuged at $20,000 \mathrm{x} \mathrm{g}$ for $10 \mathrm{~min}$. $50 \mu \mathrm{l}$ of this supernatant was mixed with $50 \mu \mathrm{l}$ SDS loading buffer ( $2 \% \mathrm{w} / \mathrm{v}$ SDS, $0.1 \% \mathrm{w} / \mathrm{v}$ Bromophenol blue, 5 mM EDTA, $125 \mathrm{mM}$ Tris pH 6.8, 15\% v/v Glycerol and $1 \% \mathrm{v} / \mathrm{v} \beta$-mercaptoethanol), boiled for $5 \mathrm{~min}$ and centrifuged at $20,000 \times \mathrm{g}$ for $5 \mathrm{~min}$. The samples $(10 \mu \mathrm{l})$ were resolved on $12 \%$ SDS-PAGE. Nitrocellulose membranes and blotting papers were soaked in CAPS buffer $(10 \mathrm{mM}$ CAPS $\mathrm{pH} 11$ ) containing $20 \%$ methanol for $10 \mathrm{~min}$. SDS-PAGE gels were soaked in the same buffer for 2 min. The blotting paper, nitrocellulose membrane and gel were assembled in a semi-dry blotter (Trans-Blot ${ }^{\oplus}$ SD semi-dry transfer cell, Biorad) and $18 \mathrm{~V}$ applied for 30 min. Blots were stained with Ponceau S solution (Sigma) for $10 \mathrm{~min}$ to view the efficiency of protein transfer and then rinsed with PBS buffer. The blots were blocked with TBS buffer $(2.7 \mathrm{mM} \mathrm{KCl}, 38 \mathrm{mM}$ Tris- $\mathrm{HCl}$ and $140 \mathrm{mM} \mathrm{NaCl} \mathrm{pH} \mathrm{8)} \mathrm{containing} \mathrm{5 \%} \mathrm{milk} \mathrm{(from} \mathrm{pow-}$ der) at room temperature for $2 \mathrm{~h}$ and then rinsed with (1x) TBS buffer. The membranes were incubated for $4 \mathrm{~h}$ at room temperature or overnight at $4{ }^{\circ} \mathrm{C}$ with $2 \mathrm{ml} 5 \%$ milk solution $1 \mu \mathrm{g} \mathrm{ml}^{-1}$ anti-FLAG antibody (Sigma) in order to detect the FLAG-tagged proteins and $6.9 \mu \mathrm{g}$ $\mathrm{ml}^{-1}$ anti-Caf1 antibody (Abcam) for Caf1 protein detection. The blots were washed with (1x) TBS buffer two times for $5 \mathrm{~min}$ at room temperature then incubated for $4 \mathrm{~h}$ at room temperature or overnight at $4{ }^{\circ} \mathrm{C}$ with $2 \mathrm{ml}$ TBS buffer containing $2.5-5 \mu \mathrm{g} \mathrm{mL}^{-1}$ anti-mouse antibody conjugated with horseradish peroxidase (Sigma). The blots were washed twice for 15 min with TBS buffer at room temperature, covered with developing solution and incubated at room temperature for a few minutes with shaking. Developing solution was prepared by dissolving $50 \mathrm{mg}$ 4-chloronaphthol in $10 \mathrm{~mL}$ methanol and mixed with $50 \mathrm{ml}$ developing buffer $(20 \mathrm{mM}$ Tris- $\mathrm{HCl}$, $140 \mathrm{mM} \mathrm{NaCl}$ and $1 \mathrm{mM} \mathrm{Na} \mathrm{HPO}_{4} \mathrm{pH}$ 7.2) containing $60 \mu \mathrm{l}$ hydrogen peroxide. The blots were dried in air and the images were taken using a gel documentation system (Gel DocTM XR+, Biorad).

\section{Bioinformatics}

Promoter sequences were predicted using the BPROM (Softberry Inc., Mount Kisco, NY, USA, http://www.softberry.com) [24] and Neural Network Promoter Prediction 2.2 (NNPP2.2, 25] webservers. Sequence alignments were generated using the Clustal Omega [40] webserver and visualised using the ESPript [41] webserver (http:// espript.ibcp.fr).

\section{Statistical analysis}

Statistical analyses were performed by one-way analysis of variance (ANOVA). Statistically significant differences between groups were then identified using a Holm-Šidák post-hoc test.

\section{Additional file}

Additional file 1: Table S1 List of constructs used in this study. Table
S2 List of primers used in this study. Table S3 Thermal cycling conditions
for RT-PCR. Table S4 Thermal cycling conditions for PCR. Table S5 Ther-
mal cycling conditions for 5' RACE. Figure S1 Schematic of primer de-
sign. A diagram of the caf1 operon present in the plasmids used in this
study is shown, with arrows corresponding to the forward and reverse
primers and placed in the approximate position where they bind. For-
ward primers are shown on top of the genes and reverse primers shown
beneath. (A) Primers used for RT-PCR are shown in red for caf1R, green
for caf1M, orange for caf1A and blue for caf1. (B) Primers used for detect-
ing the presence of intergenic regions in CDNA are shown: purple for
intergenic region I, olive for intergenic region II and dark blue for inter-
genic region III. Figure S2 Schematic of the P1, P2 and P3 regions. The
sequence of intergenic region I (INT1), located between caf1R and caf1M
is shown, highlighted in green, with the P1, P2 and P3 regions aligned
and highlighted in red, yellow and orange respectively. The ATG nucleo-
tides corresponding to the start codon of caf1M are labelled with blue tri-
angles. Figure S3 Analysis of Caf1 content in the flocculent layer (A)
Image of E. coli cultures containing the pT7-COP plasmid grown at $35^{\circ} \mathrm{C}$
for the amounts of time stated, and centrifuged in capillary tubes to visu-
alise the flocculent layer height. (B) SDS-PAGE analysis of the flocculent
layers of the cultures from (A). (C) Graph of Caf1 band intensities in arbi-
trary units, obtained by densitometry of the gel shown in (B). Figure S4
Diagram depicting 5 'RACE experimental design. Part of the caf1 operon is


shown, with caf1A in green, intergenic region III in orange and caf1 in cyan. The location of the gene specific primer binding site at the $3^{\prime}$ end of caf1 is highlighted. Using this primer, cDNA was synthesised and sequenced using the 5'RACE method. Predicted individual transcript sequences are depicted as red lines, where the length of the line represents the length of the sequence read. Only the promoter in the P2 region (responsible for transcription of the polycistronic mRNA) is present, and so the polymerase synthesises CDNA until it dissociates from the DNA. This means the majority of sequence reads continue through intergenic region III into caflA, terminating at different positions. Figure S5 Sequences obtained by $5^{\prime}$ RACE analysis of caf1 transcripts. The partial coding sequence of caf1A, followed by intergenic region III and the coding sequence of caf1 is shown (cafl operon, COP) aligned to sequence data obtained from 8 separate 5' RACE reactions. Regions of similarity are bounded by blue boxes with red text, and regions of complete conservation highlighted in red with white text. The regions corresponding to cafl $A$, intergenic region $\mathrm{II}$ and caft are underlined in green, orange and cyan respectively. (PDF $1619 \mathrm{~kb}$ )

\section{Abbreviations}

ANOVA: Analysis of variance; CU: Chaperone-usher; EPEC: Enteropathogenic Escherichia coll; PCR: Polymerase chain reaction; RACE: Rapid amplification of CDNA ends; RDEC: Rabbit diarrheagenic Escherichia coli; RT-PCR : Reverse transcription polymerase chain reaction; T3SS: Type 3 secretion system

\section{Acknowledgements}

Not applicable.

\section{Funding}

This project has been funded by the Industrial Biotechnology Catalyst (Innovate UK, BBSRC, EPSRC), award number BB/M018318/1 to support the translation, development and commercialisation of innovative Industria Biotechnology processes. A.D.A was funded on a studentship from the Higher Committee for Education Development in Iraq. I. I is funded by CRUK program grant C1443-A22095. Equipment funded by Wellcome Trust grant 056232 was used in this study. The funding bodies had no role in the design of the study, the acquisition and analysis of data or the writing of the manuscript.

\section{Availability of data and materials}

The datasets used and analysed during the current study are available from the corresponding author on reasonable request.

\section{Authors' contributions}

ADA and DTP acquired the data; ADA, DTP and II analysed the data; ADA DTP and JHL designed and conceptualized the study; DTP, HW, II, NDP and $\mathrm{JHL}$ were involved in supervision of the study; HW and NDP contributed materials towards the study; NDP and JHL acquired funding for the study; ADA, DTP and JHL wrote the manuscript, and II and HW assisted in the critical reading and revision of the manuscript. All authors have read and approved the final version of the manuscript.

\section{Ethics approval and consent to participate}

Not applicable.

\section{Consent for publication}

Not applicable

\section{Competing interests}

The authors declare that they have no competing interests.

\section{Publisher's Note}

Springer Nature remains neutral with regard to jurisdictional claims in published maps and institutional affiliations.
Received: 18 December 2018 Accepted: 25 March 2019

Published online: 29 March 2019

\section{References}

1. Shapiro RS, Cowen LE. Thermal Control of Microbial Development and Virulence: Molecular Mechanisms of Microbial Temperature Sensing. mBio. 2012;3(5):e00238-12.

2. Hoe NP, Goguen JD. Temperature sensing in Yersinia pestis: translation of the LcrF activator protein is thermally regulated. J Bacteriol. 1993;175(24): 7901-9.

3. Chakraborty S, Li M, Chatterjee C, Sivaraman J, Leung KY, Mok Y-K. Temperature and $\mathrm{mg}(2+)$ sensing by a novel PhoP-PhoQ two-component system for regulation of virulence in Edwardsiella tarda. J Biol Chem. 2010; 285(50):38876-88.

4. Albanesi D, Martín M, Trajtenberg F, Mansilla MC, Haouz A, Alzari PM, et al. Structural plasticity and catalysis regulation of a thermosensor histidine kinase. Proc Natl Acad Sci. 2009;106(38):16185.

5. Elsholz AKW, Michalik S, Zühlke D, Hecker M, Gerth U. CtsR, the grampositive master regulator of protein quality control, feels the heat. EMBO J. 2010:29(21):3621.

6. Hurme R, Berndt KD, Normark SJ, Rhen M. A proteinaceous gene regulatory thermometer in Salmonella. Cell. 1997:90(1):55-64.

7. Quade N, Mendonca C, Herbst K, Heroven AK, Ritter C, Heinz DW, et al. Structural basis for intrinsic Thermosensing by the master virulence regulator RovA of Yersinia. J Biol Chem. 2012;287(43):35796-803.

8. Perry RD, Fetherston JD. Yersinia pestis--etiologic agent of plaque. Clin Microbiol Rev. 1997;10(1):35.

9. Bertherate E. Plague around the world, 2010-2015. WHO Wkly Epidemiol Rec. 2016;91(8):89-93.

10. Du $Y$, Rosqvist $R$, Forsberg A. Role of fraction 1 antigen of Yersinia pestis in inhibition of phagocytosis. Infect Immun. 2002;70(3):1453-60.

11. Soliakov A, Harris JR, Watkinson A, Lakey JH. The structure of Yersinia pestis Caf1 polymer in free and adjuvant bound states. Vaccine. 2010;28(35):574654.

12. Sauer FG, Remaut $H$, Hultgren $\mathrm{SJ}$, Waksman $\mathrm{G}$. Fiber assembly by the chaperone-usher pathway. Biochim Biophys Acta. 2004;1694(1-3):259-67.

13. Roque Al, Soliakov A, Birch MA, Philips SR, Shah DSH, Lakey JH. Reversible Non-Stick Behaviour of a Bacterial Protein Polymer Provides a Tuneable Molecular Mimic for Cell and Tissue Engineering. Adv Mater (Deerfield Beach, Fla). 2014;26(17):2704-9.

14. Miller J, Williamson ED, Lakey JH, Pearce MJ, Jones SM, Titball RW. Macromolecular organisation of recombinant Yersinia pestis F1 antigen and the effect of structure on immunogenicity. FEMS Immunol Med Microbiol. 1998:21(3):213-21.

15. Zavialov AV, Kersley J, Korpela T, Zav'yalov VP, Maclntyre S, Knight SD. Donor strand complementation mechanism in the biogenesis of non-pilus systems. Mol Microbiol. 2002;45(4):983-95.

16. Ulusu Y, Dura G, Waller H, Benning MJ, Fulton DA, Lakey JH, et al. Thermal stability and rheological properties of the 'non-stick' Caf1 biomaterial. Biomed Mater. 2017;12(5):051001.

17. Lindler LE, Plano GV, Burland V, Mayhew GF, Blattner FR. Complete DNA sequence and detailed analysis of the Yersinia pestis KIM5 plasmid encoding murine toxin and capsular antigen. Infect Immun. 1998;66(12): 5731.

18. Gallegos MT, Schleif R, Bairoch A, Hofmann K, Ramos JL. Arac/XylS family of transcriptional regulators. Microbiol Mol Biol Rev. 1997;61 (4):393-410.

19. Galyov EE, Smirnov O, Karlishev AV, Volkovoy Kl, Denesyuk Al, Nazimov IV, et al. Nucleotide sequence of the Yersinia pestis gene encoding F1 antigen and the primary structure of the protein. Putative $T$ and B cell epitopes. FEBS Lett. 1990;277(1-2):230-2.

20. Han $Y$, Zhou D, Pang X, Song Y, Zhang L, Bao J, et al. Microarray analysis of temperature-induced transcriptome of Yersinia pestis. Microbiol Immunol. 2004:48(11):791-805.

21. Motin VL, Georgescu AM, Fitch JP, Gu PP, Nelson DO, Mabery SL, et al. Temporal global changes in gene expression during temperature transition in Yersinia pestis. J Bacteriol. 2004:186(18):6298-305.

22. Karlyshev AV, Galyov EE, Abramov VM. Zav, Yalov VP. Caf1R gene and its role in the regulation of capsule formation of Y. Pestis. FEBS Lett. 1992; 305(1):37-40.

23. Galyov EE, Karlishev AV, Chernovskaya TV, Dolgikh DA, Smirnov OY, Volkovoy Kl, et al. Expression of the envelope antigen F1 of Yersinia pestis is 
mediated by the product of caf1M gene having homology with the chaperone protein PapD of Escherichia coli. FEBS Lett. 1991;286(1):79-82.

24. Solovyev V, Salamov A. Automatic Annotation of Microbial Genomes and Metagenomic Sequences. In: Li RW, Ed. Metagenomics and its Applications in Agriculture, Biomedicine and Environmental Studies. Hauppauge, NY: Nova Science Publishers; 2011. p. 61-78.

25. Reese MG. Application of a time-delay neural network to promoter annotation in the Drosophila melanogaster genome. Comput Chem. 2001; 26(1):51-6.

26. Robison K, McGuire AM, Church GM. A comprehensive library of DNAbinding site matrices for 55 proteins applied to the complete Escherichia coli K-12 genome11Edited by R Ebright. J Mol Biol. 1998;284(2):241-54

27. von Hippel PH, Revzin A, Gross CA, Wang AC. Non-specific DNA Binding of genome regulating proteins as a biological control mechanism: I. The lac operon: equilibrium aspects. Proc Natl Acad Sci U S A 1974:71(12):4808-12.

28. Guzman LM, Belin D, Carson MJ, Beckwith J. Tight regulation, modulation, and high-level expression by vectors containing the arabinose PBAD promoter. J Bacteriol. 1995;177(14):4121.

29. Chamberlin M, Ring J. Characterization of T7-specific ribonucleic acid polymerase: II. INHIBITORS OF THE ENZYME AND THEIR APPLICATION TO THE STUDY OF THE ENZYMATIC REACTION. J Biol Chem. 1973;248(6):224550.

30. Hui MP, Foley PI Fau - Belasco JG, Belasco JG. Messenger RNA degradation in bacterial cells. (1545-2948 (Electronic)).

31. Cathelyn JS, Crosby SD, Lathem WW, Goldman WE, Miller VL. RovA, a global regulator of Yersinia pestis, specifically required for bubonic plague. Proc Natl Acad Sci. 2006;103(36):13514

32. Finn RD, Attwood TK, Babbitt PC, Bateman A, Bork P, Bridge AJ, et al. InterPro in 2017-beyond protein family and domain annotations. Nucleic Acids Res. 2017;45(Database issue):D190-D9.

33. Griffith KL, Fitzpatrick MM, Keen EF, Wolf RE. Two functions of the Cterminal domain of Escherichia coli rob: mediating "sequestration-dispersal" as a novel off-on switch for regulating Rob's activity as a transcription activator and preventing degradation of rob by Lon protease. J Mol Biol. 2009:388(3):415-30.

34. Taliaferro LP, Keen Ef 3rd Fau - Sanchez-Alberola N, Sanchez-Alberola N Fau - Wolf RE, Jr., Wolf RE, Jr. Transcription activation by Escherichia coli Rob at class II promoters: protein-protein interactions between Rob's N-terminal domain and the $\sigma(70)$ subunit of RNA polymerase. (1089-8638 (Electronic)).

35. Ariza RR, Li Z, Ringstad N, Demple B. Activation of multiple antibiotic resistance and binding of stress-inducible promoters by Escherichia coli rob protein. J Bacteriol. 1995;177(7):1655-61.

36. Barbosa TM, Levy SB. Differential Expression of over 60 Chromosomal Genes in \&lt;em\&gt;Escherichia coli\&lt;/em\&gt; by Constitutive Expression of MarA. J Bacteriol. 2000;182(12):3467.

37. Scaletsky ICA, Michalski J, Torres AG, Dulquer MV, Kaper JB. Identification and characterization of the locus for diffuse adherence, which encodes a novel Afimbrial Adhesin found in atypical Enteropathogenic Escherichia coli. Infect Immun. 2005;73(8):4753-65.

38. Cantey JR, Blake RK, Williford JR, Moseley SL. Characterization of the Escherichia coliAF/R1 pilus operon: novel genes necessary for transcriptional regulation and for pilus-mediated adherence. Infect Immun. 1999;67(5): 2292-8.

39. Rapid amplification of $5^{\prime}$ complementary DNA ends (5' RACE). Nature Methods. 2005:2:629.

40. Sievers F, Wilm A, Dineen D, Gibson TJ, Karplus K, Li W, et al. Fast, scalable generation of high-quality protein multiple sequence alignments using Clustal Omega. Mol Syst Biol. 2011;7:539 Available from: http://europepmc org/abstract/MED/21988835.

41. Robert $X$, Gouet P. Deciphering key features in protein structures with the new ENDscript server. Nucleic Acids Res. 2014:42(W1):W320-W4.

\section{Ready to submit your research? Choose BMC and benefit from}

- fast, convenient online submission

- thorough peer review by experienced researchers in your field

- rapid publication on acceptance

- support for research data, including large and complex data types

- gold Open Access which fosters wider collaboration and increased citations

- maximum visibility for your research: over $100 \mathrm{M}$ website views per year

At $\mathrm{BMC}$, research is always in progress.

Learn more biomedcentral.com/submissions 